\title{
Pela cidade, educabilidades (Príncipe, Rio Grande do Norte - século XIX)
}

\section{City and educability (Príncipe, Rio Grande do Norte - nineteenth century)}

\author{
Olivia Morais Medeiros Neta ${ }^{1}$
}

\begin{abstract}
RESUMO
Esse trabalho tem como temática cidade e educabilidade e como objeto pedagogias da cidade no Príncipe no século XIX, a partir do qual objetivamos pela relação entre os espaços e as sociabilidades, mirar um conjunto de educabilidades constituídas por práticas sociais e valores da vida material e das elaborações simbólicas no Príncipe (atual cidade de Caicó, RN) no século XIX. O corpus documental para o estudo da pedagogia da cidade no Príncipe, no século XIX, é composto por fontes político-administrativas, eclesiásticas, cartoriais e judiciárias. Esse trabalho de história cultural da cidade, para a análise e interpretação das fontes, assenta-se no método indiciário, permitindo o apreço aos pormenores e a conciliação entre a racionalidade e a sensibilidade.
\end{abstract}

Palavras-chave: Príncipe (Rio Grande do Norte); sociabilidades; educabilidades.

\begin{abstract}
This work has city and educability as its theme and pedagogies of the city in Principe in the nineteenth century as its object, from which we objectify the relationship between space and sociability, targeting a set of constituted educabilities through social practices and material life values and symbolic elaborations in Príncipe (the present city of Caicó, RN) in the nineteenth century. The documentary corpus for the study of city pedagogy in Príncipe in the nineteenth century consists of political-administrative, ecclesiastical, judicial and notary sources. This work considers the cultural history of the
\end{abstract}

1 Instituto Federal de Educação, Ciência e Tecnologia do Rio Grande do Norte. Natal, Rio Grande do Norte, Brasil. Programa de Pós-Graduação em Educação Profissional. Rua Dr. Nilo Bezerra Ramalho, 1692 - Tirol. CEP: 59015-300. 
city for the analysis and interpretation of sources, based on the evidentiary method, allowing an appreciation for details and a reconciliation between rationality and sensitivity.

Keywords: Príncipe (Rio Grande do Norte); sociability; educability.

\section{Cidade e educabilidade...}

As educabilidades remetem aos atos do aprender e podem perpassar práticas sociais em casa e em família, na rua, nos prédios e cerimônias públicas. Nessa perspectiva, esse texto objetiva pela relação entre os espaços e as sociabilidades, mirar um conjunto de educabilidades constituídas por práticas sociais e valores da vida material e das elaborações simbólicas no Príncipe (atual cidade de Caicó, Rio Grande do Norte) no século XIX.

Considerando que as educabilidades no século XIX inculcavam formas de comportar-se, sentir, de ver e estar em sociabilidade (AGULHON, 1984), focalizamos as aprendizagens, as formas de ser e fazer decorrentes das práticas sociais, sejam no espaço público ou privado, nas sociabilidades político-administrativas, religiosas e socioculturais, pois essas têm orientações pedagógicas distintas, têm uma dada hermenêutica, são veículos de enunciados pedagógicos.

Se a cidade é entendida com uma orientação pedagógica, a história cultural aqui empreendida, de conformidade com Roger Chartier (1990) e Peter Burke (2002), se constitui enquanto dimensão histórica, sendo considerada como o estudo dos processos com os quais se constrói sentidos, pois é preciso aproximá-la das configurações sociais e conceituais de um tempo e de um espaço próprios.

O corpus documental para o estudo da pedagogia da cidade no Príncipe, no século XIX, é composto por fontes distintas e amplas. São elas: político-administrativas, eclesiásticas, cartoriais e judiciárias.

Para a análise e interpretação das fontes, o estudo assenta-se no método indiciário, permitindo o apreço aos pormenores e a conciliação entre a racionalidade e a sensibilidade, constituindo-se em uma pesquisa minuciosa e detalhada. Partimos do entendimento de que a pesquisa indiciária resulta da articulação de princípios e de procedimentos heurísticos centrados nos detalhes, nos indícios e nos sinais, constituindo a noção ampla de documento, como as nossas fontes anteriormente apresentadas (GINZBURG, 1989).

Assim, este é um trabalho de história da cidade, ou mais precisamente, uma história cultural da cidade que relaciona as sociabilidades às educabili- 
dades e permanece atenta à emissão de enunciados para um entendimento de pedagogia da cidade.

\section{O Príncipe e educabilidades político-administrativas}

No Príncipe eventos como as reuniões da edilidade ou as sessões do júri e as aplicações de suas sentenças produziam aprendizagens quanto à pedagogia urbana, às leis e às normas desejadas aos habitantes da urbe. O conjunto de aprendizagens daí decorrentes pode ser congregado nas educabilidades político-administrativas que orientavam pela inculcação da norma, dos desejos ao estilo de vida urbano e dos saberes jurídicos.

Com isso, as educabilidades que perpassavam o modus vivendi dos habitantes do Príncipe no século XIX se configuravam como “[...] padrão de hábitos e comportamento a que a sociedade de uma dada época procurou acostumar o indivíduo." (ELIAS, 1994, p. 95). A busca por esse padrão constituía educabilidades a partir dos desejos e práticas de civilidade assentadas numa disciplina que objetivava gerir a população. "E gerir a população não queria dizer simplesmente gerir a massa coletiva dos fenômenos ou geri-los somente ao nível de seus resultados globais. Gerir a população significa geri-la em profundidade, minuciosamente, no detalhe." (FOUCAULT, 1981, p. 171).

Nesses termos, as educabilidades político-administrativas no Príncipe ao longo do século XIX eram cortadas pelo poder que, pelo nexo soberania-disciplina-gestão governamental exprimiam uma prática ordenadora e instituidora que tinha "[...] na população seu alvo principal e nos dispositivos de segurança seus mecanismos essenciais." (FOUCAULT, 1981, p. 171).

Essas educabilidades assentadas na disciplina passavam pelas instruções da municipalidade que pelas posturas e mesmo códigos de posturas ou por leis municipais orientavam os habitantes quanto ao estilo de vida no Príncipe. Com isso veiculavam regras, códigos, proibições, modelos de comportamentos e de atitudes em que se buscava ordenar os espaços e os corpos.

Esse estilo de vida era pensado pelas deliberações da municipalidade visando o aprender na cidade, pois a cidade como esse veículo de enunciado pedagógico operava tal qual um pedagogo que visava "[...] modificar os corpos e as subjetividades das demais pessoas, modelando-as, produzindo marcações, emitindo regras para estar no mundo, o que implica em propor um dado uso dos espaços.” (ALBUQUERQUE JÚNIOR, [2008?], p. 2). 
A exemplo, a Câmara Municipal, através de posturas de 1835, orientava o comércio e práticas socioculturais como os espetáculos públicos. (VILLA DO PRÍNCIPE, 1835). Pelos mecanismos de licenças e multas instalava o controle do estilo de vida urbano, pois as negociações de fazendas, bebidas ou miudezas deveriam atender as orientações de licenças e de seus pagamentos mensais ou por feira.

O não cumprimento dos pedidos de licenças e os pagamentos dos impostos acarretariam a cobrança de multas e punições com prisão e observância dos regulamentos policiais. $\mathrm{O}$ nexo entre uma licença ou a cobrança de uma multa se dava pelo cumprimento ou não do que estava estabelecido na postura municipal.

A educabilidade político-administrativa que passava pela observância das posturas ou códigos de posturas se assentava em deliberações para uma cidade desejada e por isso as educabilidades daí decorrentes eram as da norma, da disciplina em que o poder ditava e envolvia as relações dos sujeitos com os espaços e com as práticas recorrentes no meio urbano.

Por isso as educabilidades político-administrativas quando passavam pelas posturas ou códigos de posturas visavam a uma civilidade pela coerção, bem como pela busca de um padrão de civilidade que poderia atentar para os habitus dos moradores, como também para a disposição das casas e dos equipamentos públicos.

Esse padrão de civilidade buscado recorrentemente nas deliberações da municipalidade gestavam educabilidades no âmbito estético. Nas posturas municipais de 1851 esse veio estético presente na educabilidade político-administrativa fora expresso com rigor, pois determinava orientações e exigências para as construções e reformas das casas no Príncipe. (RIO GRANDE DO NORTE, 1851).

A municipalidade chamava para si o cuidado e o zelo com a cidade, suas casas e ruas, uma vez que deliberou sobre a necessidade de reformas, de construção de calçadas e degraus. E, ainda, se colocou como gestora e vigilante das ações no espaço urbano. Assim, as educabilidades político-administrativas passavam também pelo aprendizado de um padrão estético ditado pela municipalidade às casas e ruas. Era um aprendizado pelo consentimento e poder da Câmara Municipal quanto ao urbano.

A educabilidade político-administrativa também atentou à dimensão da moral com seus habitus e costumes no meio urbano. Com isso se buscava o padrão de civilidade para os habitantes da urbe. A busca por esse padrão como educabilidade pode ser percebido no conjunto de posturas e códigos de posturas do Príncipe no século XIX.

Nas posturas de 1871 há determinação expressa de condenação aos habitus de jogar lixo em ruas ou becos, com a conservação de entulhos que corroborem 
com o desaformoseamento da cidade ou mesmo as carreiras a cavalo no horário entre seis horas da tarde e seis horas da manhã. (CIDADE DO PRÍNCIPE, 1871). Com essas determinações os padrões de aformoseamento e práticas sociais eram incutidos àqueles que moravam no Príncipe.

Ainda no que concerne às educabilidades pelo aprendizado dos padrões de aformoseamento e práticas sociais, lembramos que as posturas municipais de 1872 ainda condenavam a prática de certos jogos e armas como a pistola e o bacamarte e também deliberam acerca do entrudo (RIO GRANDE DO NORTE, 1872).

Com isso, fica expresso que as educabilidades político-administrativas dos moradores do Príncipe tinham nas posturas anteriormente citadas a preocupação em zelar por uma cidade limpa, formosa, na qual seus habitantes se colocassem distantes de práticas perniciosas à moral e ao bem-estar da urbe. Mas, as educabilidades político-administrativas também se davam vinculadas a outros mecanismos que não as posturas e códigos de posturas.

Pensar nas educabilidades no âmbito político-administrativo é também pensar como o aparato jurídico educava. Para tanto, os processos-crime já referendados nesse trabalho nos indicam como os habitantes da urbe conviviam com a justiça e seus códigos.

A justiça e seu corpo legal expresso pelas ações de promotores, juízes e escrivães agia no emprego da lei e no julgamento de homens e mulheres pronunciados por subverterem uma norma jurídica. Essa ordem pública subvertida era a causa da abertura de inquéritos, de prisões, de exames de corpo de delito, de julgamentos e condenações.

Dessa forma, a educabilidade político-administrativa expressa no campo jurídico prezava por aprendizagens concernentes a um padrão legal de comportamento que era pautado por um ideal de disciplina que objetivava gerir a população. (FOUCAULT, 1981). Nesse sentido, o ato de roubar, de atacar alguém com pauladas ou mesmo contrariar uma lei imposta era motivo para o aparelho jurídico indiciar e punir sujeitos. Foi nessas circunstâncias que o aparelho jurídico indiciou e puniu a escrava Joana por roubo à residência do italiano Domingos Stola. Joana foi processada e pronunciada, sendo julgada na sessão solene do Tribunal do Júri em 9 de fevereiro de 1869. (RIO GRANDE DO NORTE, 1869). A sentença faz referência a artigos do Código Criminal e determina que a ré seja condenada à execução pública nas grades da cadeia.

Com júris como esse que condenou a escrava Joana o aparelho jurídico produzia educabilidades referentes às leis criminais e ao padrão jurídico de comportamento que deveria atender a uma norma imposta por regulamentos como o Código Criminal, a Constituição do Império e outros dispositivos legais. 
Assim, fosse pelas sessões do júri, pela assentada de testemunhas ou outros atos jurídicos como as sentenças e execuções, as educabilidades daí provenientes direcionavam-se às observâncias e obediências legais, pois era um aprendizado que passava pelo entendimento da justiça como um poder regulador.

Os equipamentos reguladores jurídicos ou não estavam presentes na intercessão entre os moradores do Príncipe e seu modus vivendi. Podemos perceber essa intercessão no aumento da regulação dos bens e ações. A exemplo, a necessidade das autenticações e registros de transações de compra e venda de terras, escravos e outros bens nos livros de notas do Cartório Judiciário da Comarca do Príncipe ou mesmo indicações dessas ações no escritório da Coletoria Pública, ainda no século XIX.

A Casa e Escritório da Coletoria, como um desses reguladores jurídicos, foi referenciado no processo-crime de 1875 instalado porventura da sedição contra os pesos e as medidas adotadas para o novo sistema métrico a ser utilizado no comércio, chegando a ser alvo do grupo de sediciosos que invadiram, rasgaram e queimaram papéis, leis e impostos. (RIO GRANDE DO NORTE, 1875).

O movimento de protesto contra a obrigatoriedade do uso de novas unidades de pesos e medidas ficou conhecido como quebra-quilos. Esse movimento começou na Paraíba, em 1874, e se espalhou por províncias como Pernambuco, Alagoas e Rio Grande do Norte. Os sediciosos invadiram os mercados, coletorias e as Câmaras Municipais, destruíram os novos padrões e queimaram os arquivos contábeis do governo. (MEDEIROS, 2003).

Os chamados sediciosos que se rebelaram contra o sistema métrico de pesos e medidas que passava a ser utilizado no comércio do Príncipe, assim como em outras localidades, expressaram práticas puníveis pela lei, mas ao mesmo tempo indicam que lutavam contra imposições de novos padrões métricos.

Os sediciosos demonstravam que tinham a consciência de como e quais mecanismos e equipamentos perpassavam aquele novo sistema, pois foram ao escritório da coletoria, ao cartório, à feira, ou seja, atacaram e atuaram em pontos nervais para as educabilidades e seus comportamentos padrões no que se refere às leis econômicas, no caso.

Assim como os julgamentos, as sentenças e as manifestações sociais, os eventos políticos e seus contextos orientavam e instruíam os habitantes do Príncipe. Eventos como a abolição da escravatura, ${ }^{2}$ em 1888, ou mesmo a Pro-

2 Na segunda metade do século XIX a transição do trabalho escravo para o trabalho livre representava uma exigência da expansão capitalista pela qual pressões externas se aliavam às internas decorrentes do próprio desenvolvimento urbano, por exemplo. Nesse contexto, foram aprovadas uma série de leis como a Lei Eusébio de Queirós (1850), a Lei do Ventre Livre (1871) e a Lei Saraiva Cotegipe ou Lei dos Sexagenários (1885) que restringiam gradativamente a esfera de ação do escravismo. E, em 1888, foi assinada a Lei Áurea que tornou livre os escravos do Brasil. (COSTA, 1998). 
clamação da República, em 1889, no Brasil instauravam e exigiam aprendizados de novas posturas, novas formas de comportamento e compreensão de um estilo de vida com padrões específicos.

No Príncipe, como em todo o Brasil, o ato da Proclamação da República instaurou novas exigências político-administrativas, pois expressava a ascensão de um novo regime que trazia consigo inovações no arcabouço burocrático. Com isso as educabilidades políticas, antes assentadas num estilo de vida plasmado no império e seus equipamentos e meios de controle, passavam a exigir novas aprendizagens, como o casamento civil.

Mas não só aprendizagens de cunho legal foram proporcionadas com a proclamação. A cidade e seus símbolos também mudavam mediante as novas exigências. O Príncipe, nome que cunhou a primeira mancha urbana da Ribeira do Seridó por todo o período imperial não era mais adequado em tempos de República. O nome da cidade havia de expressar, também, os novos tempos.

Foi nesse contexto de novas aprendizagens políticas que a Cidade do Príncipe passou a chamar-se Seridó e, em um intervalo bastante curto, posteriormente foi alterado para Caicó, fato noticiado pelo $O$ Povo que se tratava de um jornal nascido e motivado por interesses explicitamente políticos. (MACÊDO, 2005).

Nesse mesmo jornal, na edição de 6 de abril de 1889, também foi publicado o Manifesto Republicano, redigido pelo acadêmico Janúncio da Nóbrega Filho, no qual denunciava a situação de atraso que vivia o sertão, cuja responsabilidade creditava diretamente ao regime monárquico. Para ele, era necessário o esforço comum de todos, para a salvação pública. Assim, conclamou em seu manifesto:

É preciso que no mais obscuro ponto do Brasil, em que existir um grupo de patriotas que sonhem com a regeneração moral e política da nossa pátria, que se levante bem alto em nome do direito, em nome da humanidade, em nome especialmente da América, o estandarte glorioso da República. (MANIFESTO..., 1988, p. 24).

Janúncio da Nóbrega Filho também convidou o povo seridoense para a organização e implantação do Centro Republicano Seridoense instalado "Aos 7 de abril de 1889, nesta cidade do Caicó (ou Príncipe), às 2 horas da tarde [...]." (PARTIDO..., 1988, p. 27). Nesse trecho do anúncio da instalação do Centro Republicano Seridoense ainda podemos perceber como o ideário republicano foi instaurando aprendizagens e desejos à cidade e seus moradores, pois ainda em 1889, antes mesmo da alteração oficial do nome da cidade para Seridó e 
posteriormente para Caicó, que só ocorreria em 1890, O Povo já apresentava a futura nomenclatura para o nome da cidade.

O Manifesto Republicano ao Povo Seridoense publicado n'O Povo foi também lido por ocasião da instalação do Club Republicano. Assim, a cidade e seus moradores vivenciaram a difusão de ideias republicanas com fervor antes do 15 de novembro de 1889, que foi noticiado n'O Povo como: "O movimento

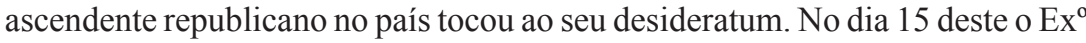
Sr. Marechal Deodoro da Fonseca à frente do Exército, da armada e do povo, proclamou, na Corte a República." (O POVO, 1988, p. 35).

No dia seguinte, em $1^{\circ}$ de dezembro de 1889 , foi festejado com toda a pompa o advento da República no Paço da Câmara Municipal. Essa comemoração assim foi noticiada:

O povo, sem distinção de classes, compareceu à uma hora da tarde no Paço da Câmara, a convite do meritíssimo Juiz de Direito, que em um brilhante discurso fez a apologia da República, explicando ao povo a vantagem da nova forma de governo. Em seguida orou o secretário do Centro Republicano Seridoense, o cidadão Basílio Gomes. (O POVO, 1988, p. 35).

Outros eventos com símbolos ligados à República também congregariam os moradores da cidade. Um desses foram os casamentos civis que, em princípio, proporcionavam ações cívicas de relevante destaque à sociedade. $O$ Povo noticiou o primeiro casamento civil ocorrido a 11 de agosto de 1890 na cidade de Caicó, o velho Príncipe. A cerimônia foi assim descrita:

Às 3 horas da tarde desceu da rua da Independência o $1^{\circ}$ juiz de paz coronel Ezequiel de Araújo Fernandes, acompanhado de uma banda de música, dirigindo-se ao lugar designado [no salão da sociedade - Amor e União].

Grande massa do povo [...] atraída pela novidade convergiu para o ponto, ficando o grande salão, a tribuna e o calçamento do edifício repletos.

A [banda de] música postada no edifício executou, após a chegada dos noivos, o hino nacional, que foi por todos ouvido de pé. Em seguida feita a leitura recomendada pela lei, foi celebrado com todo o cerimonial o casamento. [...] Findas as cerimônias civis ao som da Marselhesa, dirigiram-se os nubentes à Matriz, onde o ver.mo Vigário os uniu pelo sacramento do matrimônio. (PRIMEIRO..., 1988, p. 104). 
O Juiz, como representante legal da nova ordem, a banda de música, o hino nacional e o vigário se articulam nas cerimônias de casamento civil e religioso. No entanto, em meio a essas cerimônias estava o princípio formativo da república com as aprendizagens civis aos cidadãos, pois cerimônias como essa, passo a passo, deveriam tornar compreensível sua constituição e funcionalidade em um contexto específico.

O casamento civil era uma dessas aprendizagens que foi descrita ainda na mesma reportagem exprimindo que os seridoenses, e no caso os caicoenses "[...] apreciam os melhoramentos e as grandes reformas que em tampoucos meses de existência já nos deu o patriótico e popular governo republicano." (PRIMEIRO..., 1988, p. 105).

Dessa maneira, as educabilidades político-administrativas tecem a pedagogia urbana e as nuances associadas à municipalidade e os processos formativos vinculados às práticas sociais.

\section{O Príncipe e educabilidades religiosas}

O aprendizado na cidade dava-se de forma ampla na instância religiosa. Nela aprendia-se a comportar-se em cerimônias, a conduta e a doutrina cristã. Possibilidades de interpretações para essas aprendizagens acham-se nos indícios das práticas sociais nas igrejas, nas festas religiosas, nas reuniões das irmandades, nas escritas de testamentos quando se expressavam devoção e fé.

Cada indício de como se sociabilizavam os moradores do Príncipe em instâncias religiosas possibilita inferir o que e como esses aprendiam a fé e as posturas aceitáveis à vida como cristão, que deveria ressaltar um comportamento compatível com essa postura nas mais distintas ocasiões.

Os santos evangelhos eram lembrados e jurados nas cerimônias religiosas como missas, novenas e casamentos, mas também em cerimônias de conotação distinta como um júri e um interrogatório.

Professar a fé católica implicava cumprir e conhecer habitus próprios de uma religião que no Príncipe estava presente na memória e na história do lugar, que desde cedo viu sua trama histórica ser associada à Senhora Santa Ana, padroeira. Fosse associada ao Príncipe, ou de forma mais ampla à Freguesia e seus limites, a devoção a Santa Ana foi responsável por pedidos de pertencimento aos limites religiosos de sua freguesia.

A exemplo, os moradores da fazenda Espírito Santo que, pela provisão de 10 de julho de 1788, do Bispo Dom Diôgo de Jesus Jardim, deveriam con- 
gregar na Freguesia de Nossa Senhora da Guia com sede em Patos requereram continuar a pertencer à Freguesia de Santa Ana "[...] da Vila Nova do Príncipe, d'onde sempre foram." (FREGUESIA..., 1748-1906, f. 10).

Santa Ana como padroeira era evocada por padres e vigários nos sermões e ofícios na Matriz. Era celebrada em julho como Padroeira do Príncipe e da Freguesia, era reverenciada na Irmandade por seus devotos e dessa forma podemos dizer que os moradores do príncipe aprendiam que Santa Ana era Senhora e Protetora do lugar e daqueles que lá habitavam.

Ser freguês de Santa Ana era partilhar de usos e costumes próprios àquele espaço, o Príncipe e os limites da freguesia, isso no que concerne às práticas religiosas católicas, pois conhecer os usos e costumes da freguesia era uma forma de estabelecer a paz entre os párocos e os paroquianos. Esses usos e costumes versavam sobre os salários referentes aos enterros, ofícios, licenças de batismo e de casamento, festas e tudo mais que pertencesse aos direitos paroquiais. (FREGUESIA..., 1748-1906, f. 15).

Com isso, párocos e fregueses sabiam o quanto equivalia em termos monetários cada ação. Pelos testamentos podemos inferir quais as esmolas de costumes para capelas de missas, ofícios, visita de covas e outras ações ou ritos. As contas do funeral de Luiz de Fontes Rangel, de março de 1832, trazem valores referentes à missa de corpo presente, acompanhamento, encomendação e velas, sinais e ofício paroquial. Desses itens listados nas contas do funeral foi o ofício paroquial o mais oneroso, custou $10 \$ 00$.

Esse item, ofício paroquial, também é comum a outras contas de funeral, como as de Joaquina Maria do Nascimento (1851), sepultada em agosto de 1851, e de Dona Antônia Maria de Jesus (1854), sepultada em fevereiro de 1854. Considerando que o intervalo de uma para outra conta é próximo podemos perceber que, mesmo assim, existem diferenças nos valores, uma vez que nas contas do funeral de Dona Joaquina Maria do Nascimento o ofício paroquial correspondeu a $10 \$ 00$ e no de Dona Antônia o ofício paroquial correspondeu a $14 \$ 00$.

Nessas duas contas de funerais podemos considerar que se aprendia a requerer comportamento ou ações-padrão no momento da morte. Um desses comportamentos diz respeito à visita de covas, que podia constar de sinal e missa de sétimo dia.

Os usos e costumes, assim, melhor distribuíam a intercessão dos paroquianos com a igreja, o que reforçava comportamentos e ações do católico cristão em diversas fases de sua vida. Entretanto, outros dispositivos também faziam parte das disposições aos cristãos. Um deles era o conhecimento do recebimento de pastorais e editais por parte do Bispado.

As pastorais e os editais recebidos na Freguesia de Santa Ana eram tornados públicos, isso por determinação do órgão expedidor, no caso do Príncipe 
o Bispado de Olinda. Assim ocorreu com a carta pastoral do Bispo Dom José Joaquim taxando a esmola da Missa, determinada para a sustentação diária do sacerdote: "[...] fique taxada a Esmola da missa na quantia de trezentos e vinte réis, e na de quatrocentos réis sendo de corpo presente [...]." (FREGUESIA..., 1748-1906, f. 18 v).

A publicação dessas pastorais e editais instruía pelas deliberações de como comportar-se, do que deveria fazer e seguir um católico. Na pastoral de 18 de maio de 1853, o Bispo Dom João da Purificação Marques Perdigão pede que os fiéis cumpram as "[...] observâncias recomendadas pelo supremo Chefe da Igreja [...]" e mais, implora "[...] a solicitude das Competentes Autoridades, a fim de que tenha a sua devida e plena execução a providente Lei relativa a santificação dos dias de guarda [...]." (FREGUESIA..., 1748-1906, f. 25).

Cumprir as observâncias recomendadas pelo Supremo Chefe da Igreja era uma educabilidade que se constituía mediante a palavra proferida e escrita, pois existia a determinação de que as pastorais e editais fossem publicados "[...] em todas as Freguezias desta Diocese, à Estação da Missa Paroquial em três dias Festivos e Registrado no competente Livro.”(FREGUESIA..., 1748-1906, f. 25).

Às missas dominicais afluíam os paroquianos que assistiam a pregação da palavra, a homilia dos sacerdotes e pela palavra ouvida introjetavam usos e costumes como os expressos na pastoral de 18 de maio de 1853, pelo Bispo Dom João da Purificação Marques Perdigão, que se referia aos dias santos, às abstenções e aos jejuns.

As educabilidades vinculadas aos aprendizados decorrentes de sociabilidades religiosas versavam, em sua maioria, acerca da ação dos fiéis, de seus habitus frente à Igreja Católica e suas cerimônias religiosas e festivas seja para glorificar a Senhora Santa Ana, os santos protetores ou mesmo a celebração das exéquias solenes que se direcionavam à renovação da fé dos católicos e para o aprimoramento de comportamentos e atitudes ligados a uma vida religiosa.

Um dos eventos de maior concentração e relevância às educabilidades no Príncipe no que concerne à religião era a festa da padroeira. A Festa de Santa Ana era realizada no mês de julho, mas sofreu alterações em suas disposições ao longo dos anos. Algumas dessas alterações atendiam a disposições gerais da igreja que regulavam datas e eventos que deveriam compor a festividade. Vejamos uma dessas regulações:

[...] as festas dos Santos Patronos ou Oragos das Diocezes, Cidades, Lugares, e Paróquias do Império do Brasil sejam transferidos, em quanto ao que é extrínseco para o respectivo Domingo que imediatamente seguir, somente com missa solene dos mesmos, segundo as rubricas; 
transferida porém, como acima, a Festa do mesmo Santo, possamos o jejum da Vigília, se em algum lugar se devia abservarão para o Sábado, que precede o mesmo domingo. (FREGUESIA..., 1748-1906, f. 25 v).

Com isso as festas aos Santos patronos ou oragos no Brasil deveriam ter data móvel, sendo a festividade seguida ao domingo próximo aos dias dos santos e santas. Essa disposição está expressa no livro de tombo da Freguesia da Santa Ana e considerando essa deliberação supomos que assim passou a se organizar os festejos à padroeira do Príncipe.

Esse aprendizado não tinha um tempo e um espaço próprio e determinado para cada sujeito, ele perpassava o modus vivendi de todos aqueles que habitavam o Príncipe que, como sede da Freguesia da Gloriosa Senhora Santa Ana, nos cultos e celebrações sociais lembravam e referenciavam a Santa Ana como Mãe e Senhora.

A intercessão de Santa Ana era buscada e clamada em ocasiões como a escrita dos testamentos, nos quais muitos dos testadores encomendavam sua alma e pediam para que Santa Ana a levasse segura ao Reino do Céu. Com isso podemos perceber como Santa Ana era referenciada por seus fiéis, sendo indicativo de como esses apreendiam sua função e representação.

As educabilidades decorrentes das instâncias religiosas no Príncipe tinham em Santa Ana uma temática central, mas essas educabilidades também se processavam através de símbolos e signos diversos como as insígnias e estatutos das irmandades, os livros religiosos, os oratórios particulares e outros elementos que também estavam presentes no modus vivendi no Príncipe.

\section{Educabilidades socioculturais no Príncipe do século XIX}

As educabilidades socioculturais no Príncipe davam-se pela socialização em casa e em família com a apropriação e circulação de hábitos e ideias, como vimos anteriormente, e também ocorriam nos espaços mais distintos da urbe. A rua orientava e instruía, pois nela se dava o aprender da cidade, uma vez que, conforme destacou Trilla (1999), essa pode ser considerada como agente informal de educação.

A rua como o cerne do aprender da cidade e espaço emblemático de relações sociais clamava olhares de instituições como a Câmara Municipal 
que deliberava sobre práticas em espaços públicos. Os moradores do Príncipe aprendiam da cidade os horários e funções de certos espaços e suas concessões.

A cidade com um padrão de comportamento e civilidade demarcava um estilo de vida urbano que cadenciava o tempo urbano pelas proibições ou permissões. Dessa forma, essa cadência obedecia a maior ou a menor intensidade de práticas públicas, de vozerias, de movimento acintoso nas vias da cidade.

O tempo urbano era cadenciado então pelo tempo do silêncio, que deveria ser prezado e recorrente nas noites no Príncipe. Esse tempo do silêncio era impresso por determinações como a da postura municipal de 1855 que orientava que eram "[...] prohibidas as funcções com vozerias dentro desta villa, depois das nove horas da noite, de modo que perturbem o socêgo público [...]." (RIO GRANDE DO NORTE, 1855, p. 57).

O sossego público após as nove horas da noite deveria ser, então, um dos itens que os moradores aprendiam da cidade. Porém, esse tempo do sossego sofria alterações ou exceções nos tempos de festa de Santa Ana ou nas oitavas de Natal.

Os moradores aprendiam com a cidade que o tempo das ações e práticas também requeria cadência. O movimento nos becos ou vias públicas em transportes como os cavalos necessitavam de instruções e, certamente para o bem-estar e o bom fluxo citadino, deveriam ser apreendidos pelos moradores do Príncipe.

Por esse motivo as posturas da Câmara Municipal de 1871 atentavam que era expressamente proibido "[...] esquipar a cavallo, ou fazer correrias nas ruas d'esta cidade e povoações do Município das 6 horas da tarde as 6 horas da manhã, e das 5 horas da tarde em diante no tempo da Festa de Sant'Anna." (CIDADE DO PRÍNCIPE, 1871, f. 2).

Nesse sentido, as educabilidades socioculturais direcionavam as ações e práticas dos moradores do Príncipe para um dado padrão de cadência do tempo urbano. E por isso mesmo, a Câmara Municipal ainda chamou à pauta a maneira de usar os cavalos em 1884, quando ditou que ninguém poderia "[...] à cavallo andar nos becos da cidade e partes da feira senão em marcha moderada [...]." (CIDADE DO PRÍNCIPE, 1884a, f. 2 v). A marcha moderada pressupunha a cautela e a prevenção de acidentes ou mesmo indiciava que o fluxo de pessoas aumentava, particularmente, em dias de feira.

Se as deliberações da Câmara Municipal projetavam um dado padrão urbano quanto ao tempo na cidade, essas também prezavam pelas funções de estabelecimentos como a Casa de Mercado Público, que ganhou regulamento em 1884.

No regulamento da Casa de Mercado Público ficou expresso que esse estabelecimento era reservado "[...] ao uso do comércio das 6 horas da manhã as 9 horas da noite $[. .$.$] e durante esse tempo o ingresso esta[ria] franqueado a todos$ excepto aos ébrios e aos loucos [...].” (CIDADE DO PRÍNCIPE, 1884b, f. 1). 
E mais, era um espaço destinado exclusivamente à comercialização de gêneros alimentícios e, portanto, os bancos e cargas de fazendas e miudezas só seriam admitidos, embora pagassem direitos, quando houvesse quadras desocupadas.

Por regulamentos como esse que orientava o funcionamento de estabelecimentos os moradores do Príncipe aprendiam da cidade que os espaços têm usos específicos, pelo menos no plano do desejado, e que nem todos têm transito livre. Com isso, os moradores aprendiam que a cidade inclui e também exclui, que ela é seletiva.

A cidade excluía ébrios e loucos de espaços como a Casa do Mercado Público, mas incluía os proprietários das bancas, os fiscais municipais e os moradores clientes ou passantes que não ferissem as instruções do referido regulamento. Os bêbados eram excluídos pela cidade não só da Casa do Mercado, mas também do espaço urbano, pois deveriam ser "[...] postos em custódia pela authoridade policial [...].” (CIDADE DO PRÍNCIPE, 1884a, f. 3).

Assim, se aprenderia da cidade o comportamento aceito e o não aceito, aquele que era incluído como padrão e aquele excluído. É nesse contexto que não só os ébrios, mas os jogadores também figuravam como excluídos. As posturas municipais proibiam os chamados jogos de parada e os jogos que fossem apostados a dinheiro.

Para coibir e demarcar essa prática ratificou-se em 1884 que "[...] é proibido jogar a dinheiro com cartas ou com qualquer meio, jogos de parada [...]", sendo ainda não aceito e passível de multa “[...] os donos de casa ou os jogadores de jogos lícitos que admitirem filhos, família, famulo ou escravos, ficando além das penas o dono da casa obrigado a pagar aos pais, tutores ou curadores, amos e senhores perdido nos jogos [...]." (CIDADE DO PRÍNCIPE, 1884a, f. 4).

A custódia para os ébrios e as multas para os donos de casa de jogos ou os jogadores eram dispositivos para que a cidade fizesse com que seus moradores aprendessem que a bebida e os jogos ilícitos não eram aceitos. Assim como também não eram aceitos comportamentos daqueles que proferissem ou escrevessem palavras obscenas. (CIDADE DO PRÍNCIPE, 1884a, f. 4).

Nesses termos, as educabilidades socioculturais direcionavam a conduta e os costumes dos moradores do Príncipe a uma civilidade moral que condenava aqueles que proferissem palavras obscenas ou cometessem atos indecentes em lugar público.

As educabilidades socioculturais no Príncipe do século XIX circunscreviam-se pela socialização em casa e em família com a apropriação e circulação de habitus e na rua com as orientações e instruções para aprender da cidade um estilo de vida urbano de conformidade com uma formação pela civilidade e seus padrões de comportamento. 
E, com essa assertiva, a transição do Império para a República no Brasil imprimiu no Príncipe uma pedagogia da nação com seus desejos de educabilidade. Para bem exprimir novas aprendizagens daí decorrentes, podemos indicar a mudança do nome do Príncipe. Os cidadãos haviam de aprender com a República que o nome tem valor e representa, por isso deve ser mudado. Assim, proclamada a República os republicanos no Seridó não se furtaram ao esforço de legitimação simbólica que a nova ordem exigia. Logo arregimentaram a mudança do nome do lugar para Seridó, já em fevereiro de $1890,{ }^{3}$ e em seguida para Caicó, em julho de 1890. (MACÊDO, 2005).

As educabilidades socioculturais nos fizeram mirar sensibilidades de outrora, mas não com o intuito de sentir ou recompor da mesma forma, e sim com o desafio de tentar explicar como poderia ter sido a experiência sensível de um outro tempo pelos indícios que nos deixou.

\section{Considerações sobre o Príncipe e suas educabilidades no século XIX}

As educabilidades político-administrativas, religiosas e socioculturais são parte da íntima e constante relação dos sujeitos com os espaços e as sociabilidades neles ocorridas, por isso muitas vezes essas eram reguladas por dispositivos que visavam "[...] tornar automático o comportamento socialmente desejável [...] fazendo com que o mesmo pareça à mente do indivíduo resultar de seu livre arbítrio e ser de interesse de sua própria saúde ou dignidade humana." (ELIAS, 1994, p. 153).

Dessa maneira, as educabilidades decorrentes das sociabilidades expressas sejam pela instância político-administrativa, seja pela religiosa ou sociocultural produziam comportamentos considerados socialmente aceitáveis, pois as educabilidades são parte da íntima e constante relação dos sujeitos com os espaços e as sociabilidades neles ocorridas. Considerando esse entendimento enfatizamos a cidade como espaço formativo, uma vez que está envolto por uma educação dos ou para os sentidos.

A veiculação dos enunciados pedagógicos do Príncipe no século XIX pela Câmara Municipal e pelos espaços públicos e privados nos proporciona identificar uma estreita relação entre o processo de organização e regulação de

3 O Decreto estadual n. 12 , de $1^{\circ}$ de fevereiro de 1890 , mudou os nomes das cidades de Imperatriz para Martins, de Príncipe para Seridó e de Villa Imperial de Papary para Vila Nova de Papary. (RIO GRANDE DO NORTE, 1896). Posteriormente, Seridó recebeu a denominação de Caicó e Vila Nova de Papary de Nízia Floresta. 
normas com a formação da civilização, de uma pedagogia à cidade e seus habitantes, uma vez que o controle das condutas estava associado ao controle social.

Enfim, a educabilidade no Príncipe no século XIX comportava tanto as orientações ditadas pela municipalidade com ênfase no bem comum, na ordem social, nos serviços públicos, quanto as que residiam numa exterioridade de práticas sociais diferenciadas, uma vez que os espaços urbanos ganham forma e vida com os passos, as ações e práticas de transeuntes, que compõem a cartografia citadina e lhes dão configuração.

Em termos conclusivos, pensar sobre cidade e educabilidade é ressaltar que a pedagogia da e na cidade é possível em função dos movimentos cidadãos e da urbanidade, bem como pela monumentalização da cidade, pois esta é responsável pela transmissão de saberes. E, ainda mais, para que seja possível uma pedagogia da cidade temos que colocar de lado uma perspectiva do fenômeno educativo reduzido aos espaços, tempos, processos e atores escolares.

A pedagogização na e pela cidade é bem constituída mediante o aprendizado do estilo de vida urbano e civilizado, do direito à cidade e sua função pedagógica expressa em projetos urbanos ou educativos, na cidade e sua hermenêutica, suas normas, condutas e sua postura sensível. Todos esses aprendizados e funções pedagógicas expressos corroboram para uma dimensão ampla da pedagogia, a da cidade.

\section{REFERENCIAS}

AGUlHON, Maurice. Penitents et Francs-Maçons de l'ancienne Provence. Paris: Fayard, 1984.

ALBUQUERQUE JÚNIOR, Durval Muniz de. Pedagogia: a arte de erigir fronteiras. [2008?]. Disponível em: $<$ http://www.cchla.ufrn.br/ppgh/docentes/durval/artigos/pedagogia_arte_de_erigir_fronteiras.pdf $>$. Acesso em: 15/09/2010.

BURKE, Peter. História e teoria social. São Paulo: Editora UNESP, 2002.

CHARTIER, Roger. A história cultural: entre práticas e representações. Rio de Janeiro: Bertrand Brasil, 1990.

CIDADE DO PRÍNCIPE. Câmara Municipal. Posturas da Câmara Municipal da Cidade do Príncipe. Cidade do Príncipe, 19 jan. 1884a. Acervo do Instituto Histórico e Geográfico do Rio Grande do Norte, Natal. (Documento avulso, Caixa 208, Maço 17). 
Posturas Municipaes da Villa do Príncipe. Cidade do Príncipe, 23 set. 1871. Acervo do Instituto Histórico e Geográfico do Rio Grande do Norte, Natal. (Documento avulso, Caixa 208, Maço 23).

- Regulamento da Casa do Mercado Público da Cidade do Príncipe. Cidade do Príncipe, 12 mar. 1884b. Acervo do Instituto Histórico e Geográfico do Rio Grande do Norte, Natal. (Documento avulso, Caixa 214).

COSTA, Emília Viotti da. Da senzala à colônia. São Paulo: Fundação Editora da UNESP, 1998.

ELIAS, Norbert. O processo civilizador: uma história dos costumes. Rio de Janeiro: Jorge Zahar, 1994. (v. 1).

FOUCAULT, Michel. Microfisica do poder. Rio de Janeiro: Graal, 1981.

FREGUESIA da Gloriosa Senhora Santa Ana do Seridó. Livro de tombo (1748-1906). Casa Paroquial São Joaquim, Paróquia de Santa Ana, Caicó-RN.

GINZBURG, Carlo. Mitos, emblemas, sinais: morfologia e história. São Paulo: Companhia das Letras, 1989.

LE GOFF, Jacques. Por amor às cidades: conversações com Jean Lebrum. São Paulo: Fundação Editora da UNESP, 1998.

MACÊDO, Muirakytan Kennedy de. A Penúltima versão do Seridó: Uma história do regionalismo seridoense. Natal: Sebo Vermelho, 2005.

MANIFESTO republicano ao povo seridoense. O Povo, Seridó, 6 abr. 1889. In: MEDEIROS FILHO, Olavo de. Caicó, cem anos atrás. Brasília: Centro Gráfico do Senado Federal, 1988, p. 24.

MEDEIROS, Paulo Herôncio de. Quebrando tradições: criminalidade e revolta do Quebra-Quilos. 80 f. Monografia (Curso de História) - Centro de Ensino Superior do Seridó, Universidade Federal do Rio Grande do Norte, Caicó, 2003.

O POVO, Seridó, 7 dez. 1889. In: MEDEIROS FILHO, Olavo de. Caicó, cem anos atrás. Brasília: Centro Gráfico do Senado Federal, 1988, p. 35.

PARTIDO Republicano. O Povo, Seridó, 13 abr. 1889. In: MEDEIROS FILHO, Olavo de. Caicó, cem anos atrás. Brasília: Centro Gráfico do Senado Federal, 1988, p. 27.

PRIMEIRO casamento civil. O Povo, Seridó, 17 ago. 1890. In: MEDEIROS FILHO, Olavo de. Caicó, cem anos atrás. Brasília: Centro Gráfico do Senado Federal, 1988, p. 104.

RIO GRANDE DO NORTE. Assembleia Legislativa Provincial. Resolução n. 235, de 19 de setembro de 1851. Aprova artigos de Posturas adicionais da Câmara Municipal da Villa do Príncipe. Coleção das leis provinciais do Rio Grande do Norte. (Tomo XIV). Natal: Typografia de J. M. Navarro, 1851. 
. Assembleia Legislativa Provincial. Resolução n. 330, de 6 de setembro de 1855: Aprova vários Artigos de Posturas adicionais da Câmara Municipal da Villa do Príncipe. Coleção de leis, decretos e resoluções da Província do Rio Grande do Norte. Pernambuco: Typographia de M. F. de Faria, 1855.

. Auto de uma carta de Guia do Doutor Juiz de Direito da Comarca para ser a ré Joanna, escrava. Cidade do Príncipe, 1869. Fundo da Comarca de Caicó, $1^{\circ}$ Cartório Judiciário, sob a custódia do Laboratório de Documentação Histórica (LABORDOC), CERES, Caicó, UFRN. (Diversos, Caixa 01, Maço 01).

. Assembleia Legislativa Provincial. Artigos de posturas da Câmara Municipal da Cidade do Príncipe. Natal, 25 out. 1872. Acervo do Instituto Histórico e Geográfico do Rio Grande do Norte, Natal. (Documento avulso, Caixa 210).

Processo-crime (Quebrakilo). Cidade do Príncipe, 1875. Fundo da Comarca de Caicó, $3^{\circ}$ Cartório Judiciário, sob a custódia do Laboratório de Documentação Histórica (LABORDOC), CERES, Caicó, UFRN. (Diversos, PC/SÉCXIX/CX. 07).

. Decreto n. 12, 1\%02/1890: muda os nomes das cidades de Imperatriz, Príncipe e Villa Imperial de Papary. Decretos do Governo do Estado do Rio Grande do Norte, 1896.

TRILLA, Jaume. Un marc teòric: la idea de ciutat educadora. In: TRILLA, Jaume et al. Les ciutats que s'eduquen. Barcelona: Diputació de Barcelona, 1999. p. 13-51.

VEIGA, Cynthia Greive. Cidadania e educação na trama da cidade: a construção de Belo Horizonte em fins do século XIX. Bragança Paulista: EDUSF, 2002.

VILLA DO PRÍNCIPE. Câmara Municipal. Posturas da Câmara Municipal da Villa do Príncipe e de Angicos. Villa do Príncipe, 20 mar.1835. Acervo do Instituto Histórico e Geográfico do Rio Grande do Norte, Natal. (Documento avulso, Caixa 208, Maço 34).

Texto recebido em 27 de outubro de 2013. Texto aprovado em 19 de dezembro de 2013. 